\title{
Ciências Humanas na formação do profissional de saúde
}

\author{
Human Sciences in the training \\ of health professionals
}

\section{Mônica Ramos Daltro' ${ }^{1}$ Luiz Paulo Carvalho Pires de Oliveira ${ }^{2}$ (1)}

1Autora para correspondência. Escola Bahiana de Medicina e Saúde Pública (Salvador). Bahia, Brasil. monicadaltro@bahiana.edu.br ${ }^{2}$ Escola Bahiana de Medicina e Saúde Pública (Salvador). Bahia, Brasil. luizoliveira@bahiana.edu.br

Que perguntas de pesquisa temos a oferecer sobre a formação do profissional de saúde? Quais os possíveis campos de investigação? Quais alternativas metodológicas nos conduzem a reflexões cientificas? Como podemos criar discurso para propor reflexão sobre os instrumentos e ambiências onde produzimos discurso acadêmico/ científico? Por fim, qual a importância de pensar o contexto produtivo da ciência e da formação em saúde? São perguntas que nos conduzem a alternativas de reflexão sobre a participação das ciências humanas na formação em saúde e da colaboração entre diferentes proposições sobre ciência.

A formação do profissional de saúde tem sido pautada numa epistemologia cartesiana que promove o uso de metodologias matematizadas que produzem conhecimentos distintos que simultaneamente salvam vidas e produzem desigualdades. Uma tradição científica derivada de desdobramentos institucionais positivista que tem a verdade sobre o mundo referenciada como produto; uma ciência revela o mundo, por isso o discurso científico diz sobre todos e é único. De outro, as ciências humanas em contraponto, organizam-se a partir de tradições científicas que rompem orientação metodológicas estreitas, que rompem supostos epistemológicos e priorizam linguagem e canais de comunicação com alteridades. Neste caso, uma ciência produz narrativas, probabilidades e reflexão, portanto é diversa em seu discurso e prima com relação ao posicionamento epistemológico de onde anuncia a reflexão. Perspectiva que sem nenhuma dúvida compõe o fazer do profissional de saúde.

Diante disso, como escolhamos um método para pesquisa? Como entender que é adequado para uma determinada investigação? A escolha por um percurso metodológico de construção de uma pesquisa está engendrada na análise e reconhecimento de que aquele método se presta com alguma suficiência para encontrar respostas a cerca do problema de pesquisa. Isso significa que a escolha do método envolve o entendimento de alcance e englobamento dos fenômenos que se pretende. Em outras palavras, o que se pretende investigar na pesquisa é compatível com este método? Nas entrelinhas fica evidente que os métodos restringem possibilidades na medida em que abrem caminhos. O que indica a fundamental competência de saber perguntar a pesquisa. 
Neste sentido, há a premência do estímulo no texto aos questionamentos.

Quando estudamos metodologia, aprendemos que saber perguntar é uma competência indispensável à um pesquisador e a um profissional de saúde. Nosso desafio é fazer leituras de contexto com vistas a identificar lacunas no conhecimento, o que pode significar um ponto de vista diferente sobre determinado fenômeno ou a invenção de algo inédito. Essa leitura precisa materializar-se com uma pergunta? Uma pergunta adequadamente formulada promove de imediato a busca de sua resolução e assim segue o processo de desenvolvimento do conhecimento científico. Cabe ao estudante desenvolver competências para manejar o conhecimento produzido a partir de delineamentos de objetivos, coerência entre a revisão de literatura e o referencial teórico; e deve eleger um caminho para encontrar as respostas, dando visibilidade a esse. Percurso que implica a realização de uma série de escolhas. Espera-se, contudo, - de forma ética - que a ciência ambicione uma produção de conhecimento que esteja voltada para o bem-estar da sociedade.

Com esse cenário, a produção científica pode se homogeneizar sem engessamentos, pois afinal, um percurso metodológico não é propriedade de uma ou outra ciência, pois nunca existe um único caminho para se chegar a uma resposta. Embora algumas formas de fazer ciência sejam consideradas de melhor ou maior valor. O que importa é que as escolhas estejam evidentes diante do produto e do processo da pesquisa. Bem como as perguntas feitas ao objeto, ao campo onde se pesquisa. O produto é o conhecimento, a reflexão, a possibilidade de evidenciar caminhos, terapêuticas ou processos de cura ou de morrer. Mas, deve fundamentalmente narrar um percurso que envolve perguntas e escolhas diante de alternativas metodológicas. Deste modo, os modos de produzir ciência são alternativas em um campo complexo de uma ciência diversa e inacabada, em constante produção.

A hierarquização dos modos de produzir conhecimento não só fragiliza a produção de conhecimento, mas inviabiliza o desenvolvimento da reflexão crítica e restringe a ciências a lógicas hegemônicas que tendem a disseminar verdades que não podem ser alcançadas. Compactuando com Paulo Freire, entendo que 'Ensinar exige risco, aceitação do novo e rejeição a qualquer forma de discriminação," (1996,pg 36 ). Quando vemos a exclusão de um método de produção científica de conhecimento, com base nas ciências humanas, nas artes, nas engenharias, no direito podemos testemunhar uma prática preconceituosa. Volta-se à vulnerabilização dos valores democrático e especialmente humanístico até então afirmados como indiscutíveis projetos políticos pedagógicos das instituições de ensino no Brasil.

É temerária a afirmação de que existe uma única forma de produzir conhecimento no campo da saúde como insistem alguns, pois a grandeza e complexidade das práticas de atenção à saúde, um campo praxiológico e produtor de conhecimento, não pode estar reduzida uma perspectiva matematizada da realidade. Chimamanda Ngozi Adichile, filósofa contemporânea, nos adverte sobre os perigos de circunscrever a história e, - inclusão nossa - uma ciência, única. Assim como uma história única, tentar sustentar uma única forma de fazer ciência se configura no exercício de abafamento de diferenças, portanto, uma prática que rouba a dignidade das pessoas, desenraiza singularidades e produz estereótipos que se prestam a sustentar estruturas de poder e desigualdades sociais.

Nosso país vive uma experiência de ataque à dignidade, à democracia, com estratégias políticas de violação, desamparo e desqualificação da ciência que vulnerabilizam o sistema público de saúde e as Ciências Humanas. Assim, consideramos importante ampliar a oferta de estudos sobre as metodologias de maior identificação conceitual com as Ciência Humanas, como possibilidade de oferecer ao estudante alicerces para uma educação interprofissional que considere as individualidades dos pacientes, a escuta qualificada, o Choosing Wisely e o profissionalismo. Ao defender uma exclusiva forma de construção do conhecimento como competência necessária ao profissional de saúde, drenam-se possibilidades de análise e de leituras sobre as formas de viver, sofrer e morrer da nossa população. 
Estudiosos sobre racismo como Fraz Fanon, Grada Kilomba, bel hooks, Boaventura Souza Santos, Silvio Almeida, insistem em analisar a ausência como evidência e o silenciamento como estratégia desenvolvida para garantia do racismo estrutural. Algo semelhante pode ser dito, quando a formação de uma categoria profissional silencia modos e percursos para construir o conhecimento e consequentemente, as bases ideológicas a serem replicadas no cotidiano profissional.
Desta forma é sublinhada a importância de construir o caminho de formação acadêmica, bem como o caminha de pesquisa que ocupa a universidade como um caminho aberto, povoado por alternativas, disposto a uma composição. De outra forma, as possibilidades de saber, de ciência e conhecimento sobre o mundo seguem ocultas, em silêncio e inoperantes. Não sabemos qual destes caminhos ou conhecimentos pode significar um caminho de cura ou saúde. 